\title{
Ocular lesions in the blue rubber bleb naevus syndrome*
}

\author{
JOHN L. CROMPTON AND DAVID TAYLOR \\ From the Department of Ophthalmology, Hospital for Sick Children, \\ Great Ormond Street, London WC1
}

SUMMARY Investigations of a neonate presenting with multiple pleomorphic vascular skin lesions enabled a clinical and histological diagnosis of blue rubber bleb naevus syndrome to be made. This child had lesions in the conjunctiva, iris, and retina, associated with local haemorrhages at the time of birth. All the lesions regressed spontaneously, and a conservative approach to management of the ocular lesions in this syndrome is therefore suggested.

In 1860 Gascoyen $^{1}$ reported an association between cutaneous 'naevi', intestinal lesions, and gastrointestinal bleeding. Almost a century later Bean ${ }^{2}$ separated the blue rubber bleb naevus syndrome (BRBNS) from the other cutaneous vascular conditions and gave the syndrome its name. Hence the BRBNS is known eponymously as the bean syndrome. Subsequently there have been many case reports in the literature, ${ }^{1-13}$ but none mention ocular lesions in detail.

\section{Case report}

A 48-hour-old male infant was admitted to the Hospital for Sick Children, London, for investigations of multiple pleomorphic skin lesions. Both parents had been investigated for infertility for several years but no drugs had been used. There was no consanguinity and no relevant family history. There were no siblings. The pregnancy was uneventful except for the use of diazepam early in the first trimester. Lower segment caesarian section was done after failed medical induction of labour. The baby was in good condition at birth, but multiple nodular lesions on the skin were noted, and he was therefore admitted for investigation (Figs. 1 and 2).

The only significant findings on general examination were the skin lesions, which were of 3 types: (1) superficial telangiectatic-like lesions $1-2 \mathrm{~cm}$ in diameter that blanched on pressure; (2) deep

* Read at the International Congress on Paediatric Ophthalmology, Sydney, November 1979.

Correspondence to Dr J. L. Crompton, 104 Broughan Place, North Adelaide, South Australia 5006. bluish, poorly circumscribed nodules up to $1.5 \mathrm{~cm}$ in diameter; and (3) Similar but more superficial purplish nodules that did not blanch. These lesions were scattered over the face, trunk, and limbs.

Initial ophthalmological examination showed the right eye to have normal anterior and posterior segments. Pupillary reactions and external ocular movements were normal, and there was no latent or manifest strabismus. The left eye had a bulbar conjunctival haemangioma upper temporally and a subconjunctival haemorrhage near the temporal limbus. In addition there was a small haemangioma in the upper temporal quadrant of the iris which had bled into the anterior iris stroma. Temporal to the left macula was a raised haemorrhagic lesion suggestive of a small arteriovenous malformation. Regular review was suggested in case recurrent hyphaema with secondary glaucoma should develop from the iris lesion or a serous retinal detachment from the posterior polar lesion.

Laser photocoagulation of the vascular lesions or sector iridectomy were considered as possible future options should treatment be necessary.

\section{INVESTIGATIONS}

Haematological investigations suggested the presence of haemolysis, but the Coombs test was negative. The bone marrow was normal. Liver function studies and ultrasound of the liver were normal. Chest, skull, and spine $x$-rays were normal. Viral titres were normal and blood cultures negative. A barium meal demonstrated normal oesophagus, stomach, duodenum, and jejunum, but the ileum showed a $12 \mathrm{~cm}$ long segment of uniform narrowing and a markedly abnormal mucosal pattern compatible with the presence of multiple mucosal 
lesions (Fig. 3). A skin biopsy report (St John's Hospital) showed dilated vascular channels present in a well circumscribed area of mid and superficial dermis (Fig. 4). The walls were lined by a single layer of endothelial cells (Fig. 5). The appearances

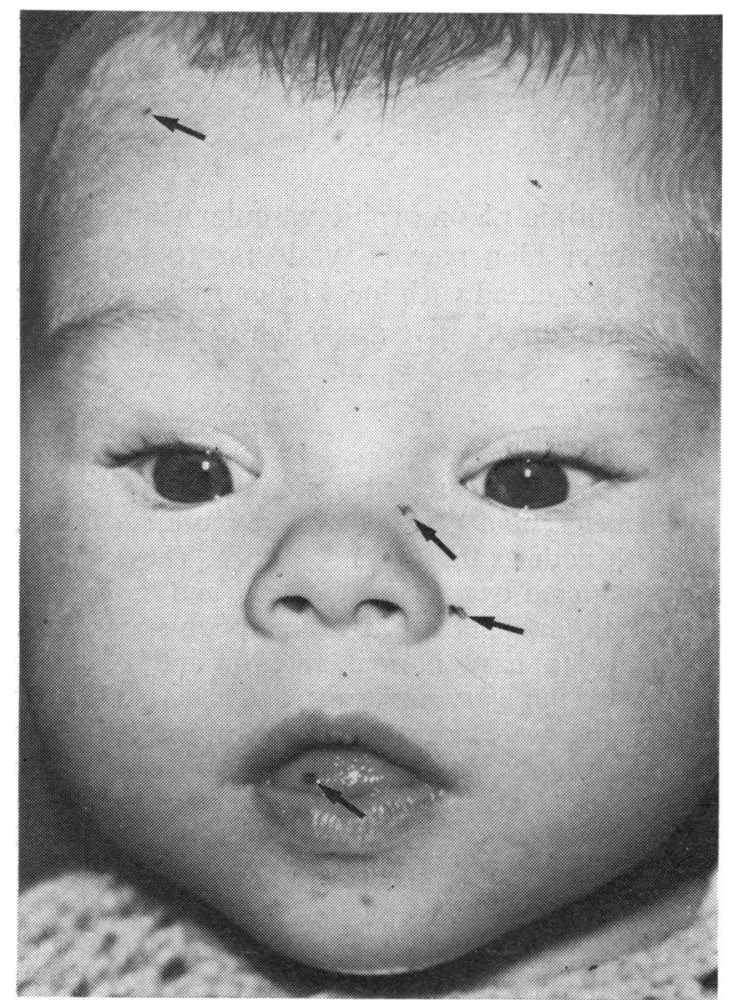

Fig. 1 Age 4 months. Haemangiomata on forehead, side of nose, and tongue (arrows).

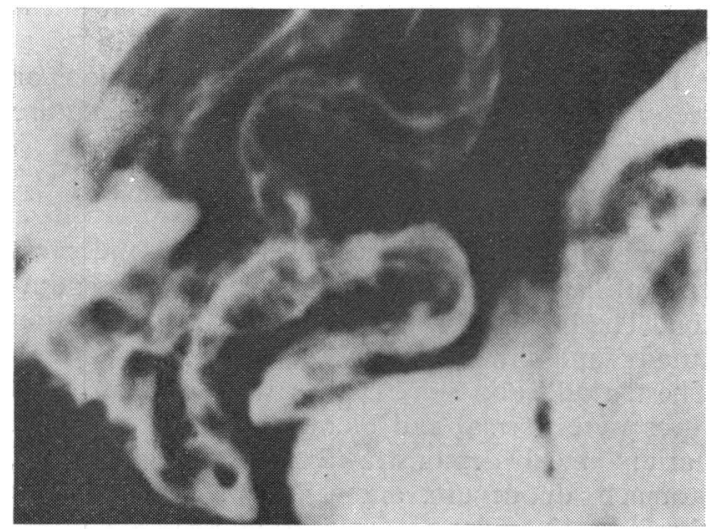

Fig. 3 Neonate. Barium meal showing uniformly narrow segment of ileum with markedly abnormal mucosal pattern. were those of a haemangioma, compatible with the BRBNS. This ruled out the alternative diagnoses of multiple glomus tumours and Fabry's disease.

\section{PROGRESS}

Severe gastrointestinal bleeding requiring blood transfusion occurred when the baby was 2 months old.

At the age of 3 months an electroencephalogram, electroretinogram, and visually evoked cortical responses were normal. Some of the cutaneous lesions had already regressed, but 5 new lesions were seen in the mouth, with 3 haemangiomata on the palate and 2 on the tongue. At examination

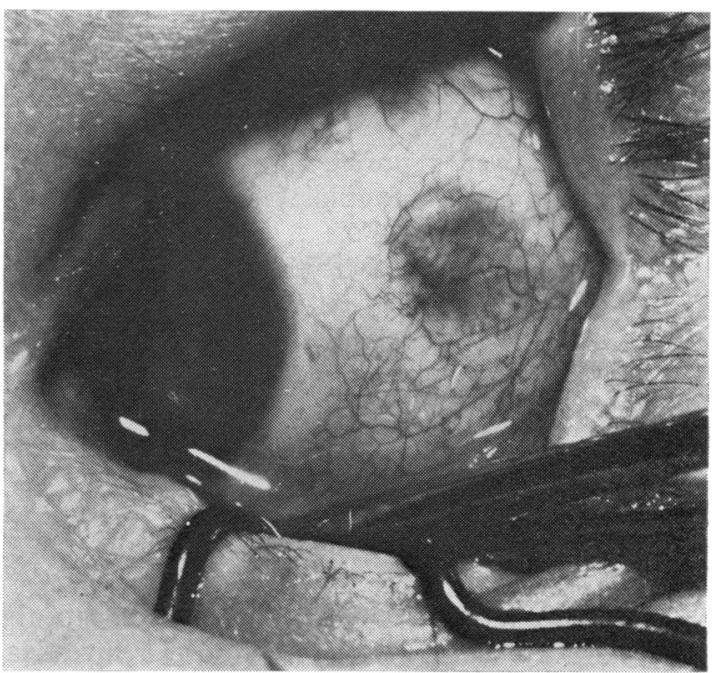

Fig. 2 Age 4 months. Subconjunctival haemangioma of left eye with overlying fibrosis.

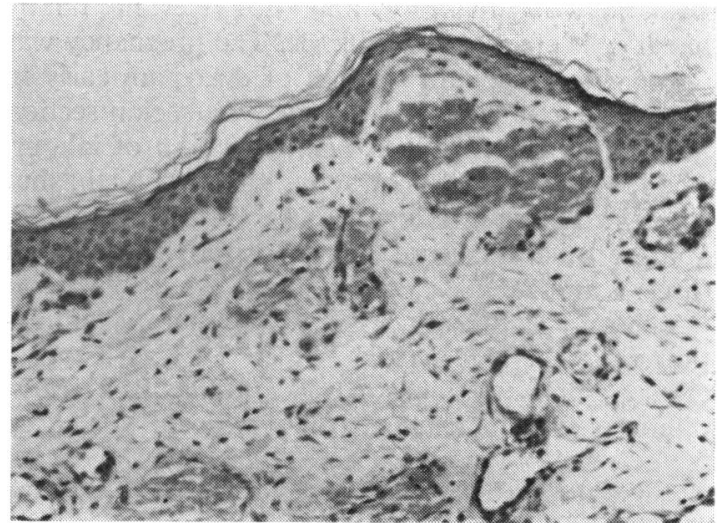

Fig. 4 Neonate. Skin biopsy (low magnification) showing multiple dilated vascular channels in the mid and superficial dermis. 
under general anaesthesia several areas of "white without pressure' were seen in the temporal peripheral retina of the right eye. The haemangioma temporal to the left macula was raised and larger, but the haemorrhage had absorbed. There were 2 inferior peripheral areas of depigmented retinal pigment epithelium. Anterior and posterior segment fluorescein angiomas confirmed the haemangiomatqus nature of the lesions (Figs. 6 and 7).

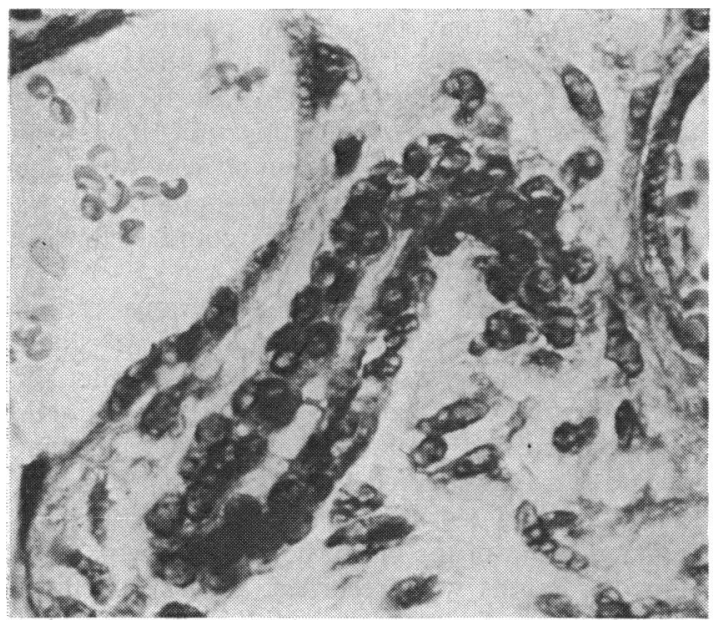

Fig. 5 Neonate. Skin biopsy (high magnification) showing dilated vascular channels lined by a single layer of endothelial cells.

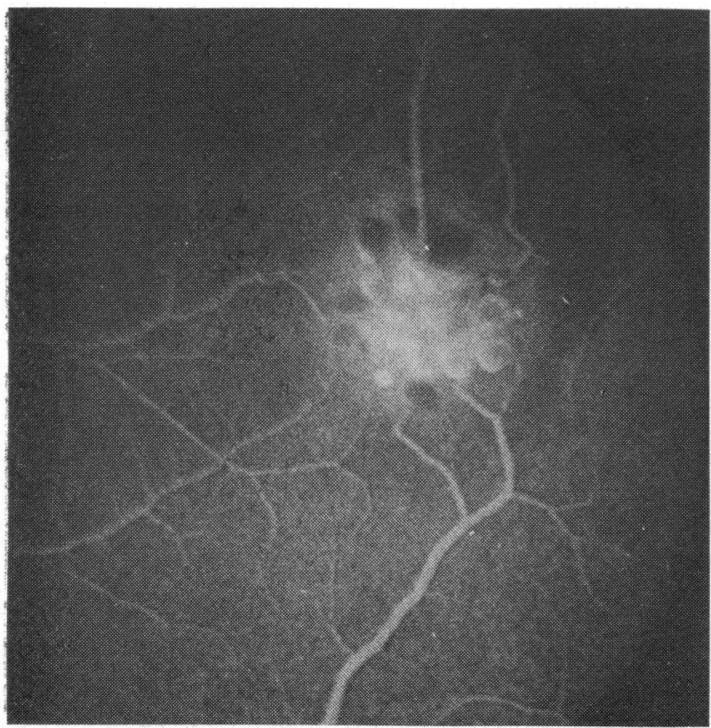

Fig. 7 Age 4 months. Fluorescein angiogram of the left fundus showing the lobulated character of the retinal cavernous haemangioma.
By the age of 7 months many of the lesions were fading, but new ones had appeared on the buttocks. No lesions were apparent in the iris. Funduscopy showed that the retinal lesions had disappeared, leaving a fairly large retinal pigment epithelial defect (Fig. 8). When the patient was last reviewed

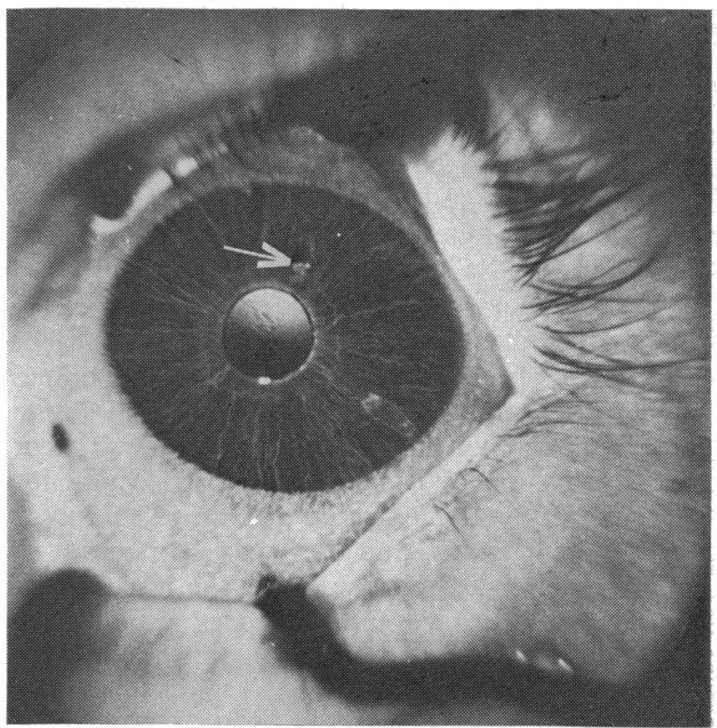

Fig. 6 Age 4 months. Fluorescein angiogram of left anterior segment showing a haemangioma (arrow) in the iris near the pupil.

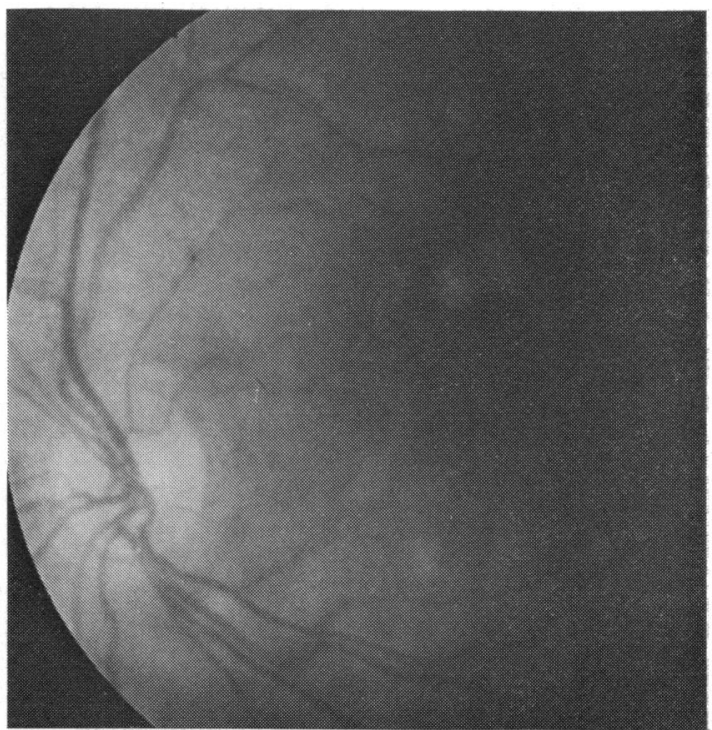

Fig. 8 Age 2 years 2 months. Fundus photograph of the left eye showing a pigment epithelial defect at the site of the previous vascular malformation. 
at 18 months of age, there had been no further ocular problems.

\section{Discussion}

Bean described 3 forms of vascular lesions: firstly, large disfiguring cavernous angiomata which can replace vital structures or obstruct an airway or alimentary canal; secondly, a compressible blood sac like a blue rubber nipple covered by milk-white skin; and, thirdly, irregular blue marked or black punctate spots whose borders merge into the skin. The second type is the typical form.

The cutaneous lesions are usually present from birth. The commonest variety are bluish red with a wrinkly surface varying in size from 0.1 to $5 \mathrm{~cm}$. Blood can be expressed from the lesions (blebs) leaving an empty sac and a depression in the surface of the skin. ${ }^{8}$ Feeding blood vessels are sometimes obvious in the skin. Any number can be found from a single lesion to many hundreds. They occur anywhere on the body but with a predilection for the trunk and arms. Profuse sweating can occur over the skin lesions, and they may be painful ${ }^{4}$ or they may be tender to palpation..$^{5}$ The histology of the lesions is variable and includes venous and cavernous haemangiomata, capillary telangiectasia, arteriovenous malformations, and venous aneurysms.

Visceral lesions are common, as is noted in $\mathbf{1 5}$ of 20 cases mentioned in one paper. ${ }^{6}$ This type of lesion can cause overt or occult gastrointestinal bleeding, but the lesions may occur in any viscera (gut, liver, adrenals, kidneys, heart, thyroid, spleen, lung, etc.), tending to spare the oral, nasal, and genitourinary mucosa.

The central nervous system is rarely involved. Waybright et al. ${ }^{7}$ described a patient with BRBNS, focal seizures, and lateralised neurological signs. Neuropathological examination revealed a clot within a vein of Galen malformation and numerous telangiectasia and haemangiomata over the surface of the posterior half of one hemisphere. Jaffe ${ }^{14}$ described a patient with cutaneous, visceral, and cervical anterior nerve root haemangiomata plus asymptomatic similar leptomeningeal lesions. Wood et al. ${ }^{15}$ found haemangiomata in the brain of a patient with cutaneous and visceral stigmata of what is now recognisable as the BRBNS.

We have been unable to find any reports of ocular vascular lesions in diagnosed cases of the BRBNS. However, Burke et al. ${ }^{16}$ described 2 such possible cases. Their first case was an infant with multiple purplish nodular haemangiomata in the skin who developed severe internal hydrocephalus requiring a ventriculo-atrial shunt. The child was blind, however, by the age of 18 months. There was a lesion (presumably vascular) in the iris of the right eye. At necropsy bilateral infarction of the occipital lobes was noted, and a pontine haemangioma was found to be obstructing the aqueduct. No mention was made of histopathological study of the eye. Their second case was a child with multiple skin lesions that seem typical of the BRBNS. Ocular examination at 5 months of age revealed 'punctate spots' twice the diameter of the retinal vessels temporal to each optic disc, and it was considered that these were possibly dilated choroidal vessels. By 1 year of age these fundal lesions were regressing, and by 28 months no. fundal lesions were seen. By this time there was. some involution of the skin lesions as well. Although no mention is made of fluorescein angiography, we consider that these fundal lesions could well have been retinal angiomata.

Gass $^{17}$ described 3 cases of cavernous retinal haemangiomata. His first patient had a single cutaneous vascular lesion in addition, while her identical twin sister had a skin lesion only. His second patient had several vascular tumours on her face and legs and suffered from grand-mal seizures. Her father had seizures and multiple cavernous. haemangiomata of the brain, but neither ocular nor cutaneous lesions were recorded. Gass's review of 9 other cases of cavernous retinal haemangioma. culled from the literature includes that of Weskamp and Cotlier $^{18}$-a 12-year-old girl with capillary vascular malformations of the skin plus a cavernous haemangioma of the brain causing seizures. The patient's father was epileptic and died from unknown causes.

Recently 2 further cases of cavernous retinal haemangiomata were reported, one of whom had skin and CNS angiomata, the other congenital cardiovascular defects and multiple neurological defects but no skin lesions. ${ }^{19}$ The latter's cavernous haemangioma underwent spontaneous partial sclerosis during a 5-year interval.

The BRBNS is transmitted in autosomal dominant fashion. ${ }^{8}$ Families with the syndrome appearing in 5,5 , and 3 successive generations were recorded by Berlyne and Berlyne ${ }^{\ominus}$ and Walshe et al.,3 supporting this mode of transmission. Many cases are sporadic, perhaps representing new mutations.

There have been a few reports of the seemingly chance association of the BRBNS with other clinical conditions: medulloblastoma, ${ }^{10}$ Maffucci's syndrome, ${ }^{5} \quad$ Klippel-Trenaunay-Weber syndrome, ${ }^{112}$ chronic lymphocytic leukaemia, and hypernephroma. ${ }^{18}$

It is evident that vascular malformations can 
occur in the skin, eye, viscera, and central nervous system or in any combination of these sites, not only in the skin and gastrointestinal tract.

The BRBNS probably qualifies for inclusion in the neuro-oculo-cutaneous group of syndromes. Our case report emphasises that the ocular aspects of this rare condition may be subtle. A conservative approach to management is recommended, as the ocular lesions may regress with the passage of time.

The assistance of Mr Martin Johns, of the Photographic Department of the Hospital for Sick Children, London, and the secretarial assistance of Miss M. Osborne are gratefully acknowledged.

\section{References}

1 Gascoyen M. Case of naevus involving the parotid gland and causing death from suffocation: naevi of the viscera. Trans Pathol Soc (Lond) 1860; 11: 267.

2 Bean WB. Blue rubber bleb naevi of the skin and gastrointestinal tract. Vascular Spiders and Related Lesions of the Skin. Springfield: Thomas, 1958: 178-85.

3 Walshe MM, Evans CD, Warin RP. Blue rubber bleb naevus. $B r$ Med J 1966; ii: 931-2.

4 Fine RM, Derbes VJ, Clark WH. Blue rubber bleb nevus. Arch Dermatol 1961; 84: 802-5.

5 Sakurane HF, Sugai T, Saito T. The association of blue rubber bleb nevus and Maffucci's syndrome. Arch Dermatol 1967; 95: 28-36.

6 Morris SJ, Kaplan SR, Ballan K, Tedesco FJ. Blue rubber bleb nevus syndrome. JAMA 1978; 239: 1887.
7 Waybright EA, Selhorst JB, Rosenblum WI, Suter CG. Blue rubber bleb nevus syndrome with CNS involvement and thrombosis of a vein of Galen malformation. Ann Neurol 1978; 3: 464-7.

8 McKusick VA. Mendelian Inheritance in Man. 5th ed. Johns Hopkins University, 1978: 50.

9 Berlyne GM, Berlyne N. Anaemia due to "blue-rubber bleb' naevus disease. Lancet 1960 ; ii: $1275-7$.

10 Rice JS, Fischer DS. Blue rubber bleb nevus syndrome. Arch Dermatol 1962; 86: 503-11.

11 Fretzin DF, Potter B. Blue rubber bleb nevus. Arch Intern Med 1965; 116: 924-9.

12 Shepherd JA. Angiomatous conditions of the gastrointestinal tract. Br J Surg 1953; 40: 409-21.

13 Hoffman T, Chasko S, Safai B. Association of the blue rubber bleb nevus syndrome with chronic lymphocytic leukemia and hypernephroma. Johns Hop Med J 1978; 142: 91-4.

14 Jaffe RH. Multiple hemangiomas of the skin and of the internal organs. Arch Pathol 1929; 7: 44-54.

15 Wood MW, White RJ, Kernohan JW. Cavernous hemangiomatosis involving the brain, spinal cord, heart, skin and kidney. Proc Mayo Clin 1957; 32: 249-54.

16 Burke EC, Winkelman RK, Strickland MK. Disseminated hemangiomatosis. Am J Dis Child 1964; 108: 418-24.

17 Gass JDM. Cavernous hemangioma of the retina-a neuro-oculo-cutaneous syndrome. Am J Ophthalmol 1971; 71: 799-814.

18 Weskamp C, Cotlier I. Angioma del cerebro y de la retina con malformaciones capillares de la Piel. Arch Oftal B Aires 1940; 15: 1 .

19 Colvard DM, Robertson DM, Trautmann JC. Cavernous hemangioma of the retina. Arch Ophthalmol 1978; 96: 2042-4. 